\title{
Un Cirujano llamado San Martín De Porras
}

\author{
A surgeon named Saint Martin De Porras
}

Emiliano Paico Vílchez ${ }^{1}$ y Emiliano Paico Zumaeta ${ }^{2}$

\section{ReSUMen}

El autor, teniendo en consideración las normas del Real Tribunal del Protomedicato del Perú, los datos biográficos del santo mulato peruano relacionados con la medicina (aprendizaje y práctica) y los testimonios de personas que fueron curadas o que vieron curar a San Martín de Porras, lo presenta como un cirujano romancista de la Lima Virreinal.

Relata algunas curaciones médico-quirúrgicas que el santo en vida terrenal realizó, clasificándolas según el método curativo empleado. Presenta también las razones o hechos que sustentan que San Martín de Porras actuó como un cirujano romancista.

Termina con el mensaje tácito que San Martín nos dejó. Es decir que nuestra profesión debemos ejercerla con presencia vigilante y solícita al lado de los enfermos, pues la actividad médica se funda sobre una relación interpersonal, en la que un hombre afligido y enfermo confía en otro hombre que puede hacerse cargo de su necesidad y que lo va a encontrar para asistirlo, cuidarlo y sanarlo. Palabras claves: San Martín de Porras, cirujano, medicina, Perú, virreinato.

\section{Abstract}

The author, taking into consideration the rules of the Real Tribunal of the Protomedicato of Perú, the biographical data of the Peruvian mulatto saint related to medicine (learning and practice), and the testimonies of people who were cured or who saw San Martín de Porras curing, presents him as a romancist surgeon of viceregal Lima.

He describes some medical - surgical cures that the saint in earthly life performed, classifying them according to the healing method used. He also presents the reasons or facts that support that San Martín de Porras acted as a romancist surgeon.

He ends with the tacit message that San Martín de Porras left us. It means that, our profession must be exercised with a vigilant and solicitous presence near the patients, because the medical activity is based on an interpersonal relationship, in which an afflicted sick

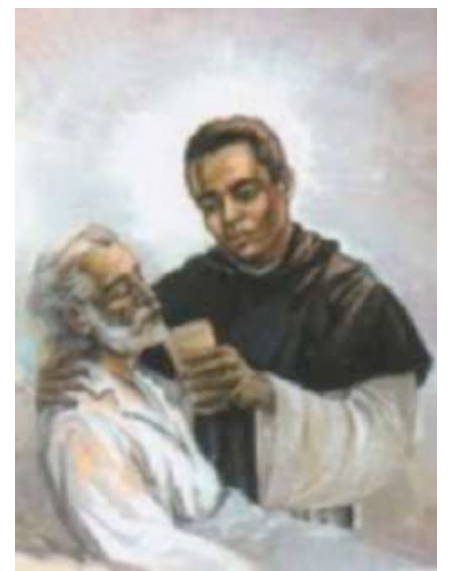

Fuente: www.ser.dominicos.org.pe/antes-que-nosotros/

trusts another man who can take care of his need and who will find him to assist, care for him and heal him.

Keywords: San Martín de Porras, surgeon, medicine, Peru, viceregal.

\section{INTRODUCCIÓN}

D esde los tiempos de Jesucristo hasta nuestros días, numerosos médicos han tenido una vida virtuosa que les ha valido estar en los altares. De otro lado están los santos o consagrados que, sin ser médicos, se esforzaron en el arte de la medicina curando enfermos. Entre los primeros está San Lucas,

1 Profesor de la Universidad Privada Antenor Orrego y cirujano pediátrico del Hospital Belén de Trujillo.

2 Estudiante becario de la Facultad de Ciencias de la Comunicación de la Universidad Privada Antenor Orrego, Trujillo. 
autor del tercer evangelio, a quien se le puede considerar como el más representativo del grupo de los médicos. Entre los segundos, se puede mencionar a San Martín de Porras, santo peruano, quien ejerció la medicina, sobre todo con los desahuciados o con la gente pobre de la Lima virreinal.

La habilidad y fama que tuvo Martín de Porras como cirujano y curador de enfermos no es muy conocida debido, probablemente, a que su actividad mística eclipsa de alguna manera el arte que aprendió desde muy tierna edad. Sin embargo, sus biógrafos presentan valiosos testimonios de la época que indican que no solamente ejerció la función de cirujano sino que la ejecutó de una manera efectiva y singular. (1-4) "Yo te curo, Dios te sana" era la frase que siempre solía decir", como diciendo, yo pongo el remedio de mi parte $y$, si te curas, es por obra de Dios y no mía; y, así evitaba muestras de veneración a su persona. ${ }^{(5)}$ Según los testimonios de la época, a veces se trataba de curaciones instantáneas, en otras, bastaba tan sólo su presencia para que el enfermo desahuciado iniciara un sorprendente y firme proceso de recuperación.

Este santo mulato peruano, además de su fiel devoción a los hábitos dominicos, destacaba por sus amplios conocimientos curativos en beneficio de la salud de las personas que buscaban su ayuda. En Martín confluyeron las tradicionales prácticas curativas andinas, españolas y africanas, especialmente la primera, pues la tradición oral estaba todavía muy viva en el recuerdo de quienes, aunque varias generaciones anteriores, formaron parte del Perú precolombino, de sus creencias religiosas y de su legado cultural.

Determinar si las obras de sanación de Martín de Porras fueron actos de un médico experto o milagros de un hombre santo es difícil, pues la recuperación de los enfermos en los relatos siempre es consistente con la inmediatez o la rapidez que el caso lo requería. Si nos ceñimos a lo estipulado por el Real Tribunal del Protomedicato del Perú se puede aseverar que Martín de Porras ejerció las funciones de un cirujano romancista, con o sin licencia, no lo sabemos.

Pero, ¿Cómo era la medicina peruana en la época que Martín de Porras vivió en el mundo terrenal? y ¿De qué manera Martín de Porras practicó la cirugía? A continuación, se explicará.

\section{La Medicina en el Perú Virreinal EL GREMio Médico}

La medicina en el Perú virreinal era practicada por cuatro gremios: el de doctores en medicina o físicos, el de cirujanos (latinos y romancistas), el de barberos o flebotomistas y el de boticarios o farmacéuticos. Para el mejor desempeño de su profesión, hubo necesidad de ejercer control sobre ellos, ya que tenían la valiosa función de curar a los enfermos, además de realizar estudios sobre los productos naturales existentes en el Perú.

El Real Tribunal del Protomedicato General era la institución suprema que controlaba el ejercicio de los profesionales de la salud. Función desempeñada desde el 11 de enero de 1570. Siendo el primer protomédico general el Dr. Antonio Sánchez de Renedo, médico de cámara del virrey Francisco de Toledo, nombrado por Real Cédula el 14 de febrero de 1568. ${ }^{(6)}$

El Tribunal del Protomedicato General tenía la función de revisar los títulos de bachiller, médico o cirujano que exhibían los peticionarios; tomaba examen a quienes pretendían ejercer las profesiones de la salud; 
otorgaba autorizaciones y licencias para el ejercicio; controlaba los medicamentos, visitaba boticas; verificaba el uso y eficacia de las plantas medicinales; y, otras medidas de salubridad en general, así como los alimentos. $(6,7)$ Garantizaba el correcto ejercicio de la medicina, combatía el empirismo. También escribía la historia natural del Perú. Además, absolvía consultas del gobierno sobre el clima, las enfermedades existentes, la higiene y la salud pública en general. ${ }^{(4)}$

El Protomedicato podía nombrar sus delegados en las diferentes reparticiones del ámbito territorial, así como a los evaluadores adjuntos para la calificación de cirujanos, boticarios y flebotomistas. Gozaba de gran autonomía y defendieron sus derechos contra los intentos de imposición de los propios virreyes o de las Audiencias.

El físico o doctor en medicina, era el profesional de la salud con el grado más alto y era el más respetado. Para acceder a este título se requería de un certificado de limpieza de sangre, pues el ingreso a las universidades estaba reservado exclusivamente para los españoles de nacimiento o para los llamados criollos que eran hijos legítimos de padre o madre españoles o de sus descendientes.

El cirujano latino, era el que trataba las enfermedades llamadas externas; para lo cual se requería de habilidades y destrezas manuales propias de la cirugía. Para obtener el título de cirujano latino se exigía haber cursado estudios universitarios de lógica, metafísica, física general y particular, llegando a la categoría de bachiller; también debía acreditar prácticas al lado de un cirujano graduado. El cirujano latino rendía los exámenes en latín ante el Tribunal del Protomedicato integrado por el presidente y catedrático de Prima de
Medicina y los catedráticos de Víspera de Medicina y de Método Galénico. Además, debía estar presente un protocirujano latino.

El cirujano romancista era el que trataba enfermedades externas pero menos complejas. Se le exigía cuatro años de práctica al lado de un cirujano titulado. No se les exigía estudios de latín ni de humanidades como a los anteriores. Rendían sus exámenes en buen romance, es decir en idioma castellano.

En la categoría de cirujano romancista, estaban comprendidos los barberos o flebotomistas, que aprendían su arte en forma empírica. Además de cortar el cabello y hacer la barba, realizaban sangrías (flebotomías), extraían dientes (exodoncias), realizaban curaciones de heridas, aplicaban enemas, ventosas y cataplasmas. También estaban los sanadores, una suerte de auxiliares en la atención de enfermos, es decir los enfermeros.

Como se mencionó líneas arriba, cuatro eran los gremios que ejercían la práctica de la medicina en el Perú virreinal: el de médicos, el de cirujanos, el de barberos o flebotomistas y el de boticarios o farmacéuticos.

El gremio de los médicos era el más distinguido. Estaba integrado por médicos venidos de España (la gran mayoría), Italia y Francia. A partir del Siglo XVII, también integraban algunos médicos a quienes el Protomedicato les había conferido el título de médico, y la universidad, los grados de doctor, licenciado y bachiller.

El gremio de los cirujanos seguía en jerarquía social a gran distancia de los médicos. Tanto los cirujanos latinos como cirujanos romancistas estaban autorizados para ejercer la cirugía de la época, incluidas algunas intervenciones 
obstétricas y ginecológicas. A los que se dedicaban a la ortopedia, se le denominaba algebrista. El gremio estaba comprendido por cirujanos venidos de Europa, especialmente españoles, y por cirujanos formados en el Perú. El estudio de la cirugía era considerado poco decoroso y visto con desprecio por las clases elevadas. El maestro Juan Lastres anota lo siguiente: "Solamente podian estudiar cirugía aquellos malnacidos, porque era un arte para gente de color, y estos la habian desempeñado durante los tres siglos virreinales." (8)

El gremio de los barberos o flebotomistas tenían una jerarquía aún inferior a la de los cirujanos. Aprendían su arte en forma empírica, prodigando el recurso heroico de la sangría. Y, por último, estaban los boticarios o farmacéuticos. Además, estaban las comadronas o recibidoras que ejercía, en competencia con la cirugía, la obstetricia e inclusive con la ginecología.

Las leyes del Protomedicato eran estrictas e inapelables. Prohibían tratar en público asuntos de medicina entre médicos y cirujanos. Al cirujano se le prohibía inmiscuirse en el ejercicio de la medicina, pues solo debía dedicarse al tratamiento de las heridas, sangrías y a operaciones quirúrgicas menores. Se consideraba delito si el médico admitiera o llamara a un cirujano para consultarle sobre algún caso clínico.

El enfermero no era graduado ni pertenecía a un gremio. Era la persona destinada a la asistencia de los enfermos y no pasaba de ser un hombre de experiencia. El enfermero menor (como lo era Martín de Porras) dependía del enfermero mayor (Martín tenía a Fray Fernando Aragonés como enfermero mayor) y ambos estaban subordinados al médico o cirujano.
Los enfermeros obtenían las medicinas del boticario (pero no podían recetar), aplicaban las curaciones prescritas y cumplían especialmente con las sangrías y purgas. No tenían iniciativa propia pero podían actuar en casos de extrema urgencia de acuerdo con su experiencia y sentido común, hasta que llegara el médico.

El enfermero mayor era el que determinaba si el enfermo debía o no internarse en la enfermería, para lo cual lo primero que hacía era tomarle el pulso. Si permanecía en la enfermería, llamaba al médico y a este correspondía diagnosticar la enfermedad del paciente y firmar las recetas para la botica.

\section{La Educación Médica}

Fundada la Universidad Nacional Mayor de San Marcos el 12 de mayo de 1551, el Virrey del Perú Luis Jerónimo de Cabrera y Bobadilla (Conde de Chinchón) crea, el 11 de octubre de 1634, dos cátedras de medicina: Prima de Medicina y Vísperas de Medicina, dando inicio así a la enseñanza oficial de la medicina en el Perú. La Prima de Medicina se dictaba por la mañana y la Víspera de Medicina por la tarde. ${ }^{(6,8,9)}$ Las cátedras fueron de estilo europeo - escolástico, es decir clases teóricas, en las que el catedrático sólo se limitaba a dar lectura a un texto, que luego se comentaba dando referencia a grandes eruditos que de la materia tratada.

El Dr. Juan de la Vega (médico de cabecera del Conde de Chinchón) fue el primer titular de la cátedra Prima de Medicina (la de mayor categoría) y el Dr. Jerónimo Andrés Rocha fue el primer titular de la cátedra Vísperas de Medicina. ${ }^{(6,8,9)}$ 
A finales de 1691, siendo Virrey del Perú Melchor Portocarrero y Lazo de la Vega (conde de la Monclova), se crea la cátedra de Método de Galeno o de Arte Curativo, siendo su primer titular el presbítero Francisco Vargas Machuca. (8)

Por esa época el título de médico era otorgado sólo por el Protomedicato, institución encargada de evaluar a los postulantes a médicos. La universidad, sólo se encargaba de formar a los futuros postulantes. Pero, por necesidad los doctores de la cátedra universitaria podían ser también evaluadores en el Protomedicato, convirtiéndose este último en una valla burocrática.

Esta medicina, sin la anatomía era muy pobre, por no decir atrasada. Los cirujanos no tenían conocimientos de anatomía, ejercían su oficio teniendo sólo incorrectos conocimientos prácticos. Su rol era simplemente efectuar las indicaciones del médico, y en lo social, su rango era aún más modesto. Los mulatos, esclavos y negros fueron los que ejercitaban ese oficio.

Recién en 1711, siendo Virrey del Perú Diego Ladrón de Guevara (arzobispo de Quito), se crea la cátedra de Cirugía. Es la cátedra más tardía y de menor categoría. El catedrático tenía la obligación de asistir una vez por semana al mortuorio del Hospital San Andrés para hacer una demostración anatómica. Así se inicia una era de enseñanza práctica de la medicina ya que anteriormente se hacía en forma teórica, leyendo los textos de autores antiguos.

El primer catedrático nombrado a la cátedra de Anatomía fue el Dr. Joseph de Fontidueñas, clérigo que, según Valdizán), no logró desempeñar su cargo, siendo en realidad el que inició la enseñanza de Anatomía el Dr. Pedro López de los Godos en 1723. ${ }^{(9)}$

\section{LAS ENFERMEDADES}

En la época terrenal de Martín de Porras, Lima sufría de muchas enfermedades. En el Diario de Juan Antonio Suardo se mencionan las enfermedades que, muy bien las clasifica José Antonio del Busto, al que seguimos de cerca en este capítulo. ${ }^{(4,10)}$ Del Busto las clasifica de la siguiente manera: dolores, males y pestes.

Los dolores. Eran en realidad síntomas y por lo general no implicaban gravedad. Eran muy comunes y de fácil reconocimiento. Entre los más frecuentes se mencionan al dolor de cabeza, dolor de oído, dolor de muelas, dolor de estómago, dolor de costado (dolor torácico) y dolor de ijada (dolor en el hipocondrio derecho o izquierdo).

Los males. Eran dolencias mayores, no siempre fáciles de curar, y en algunos casos los enfermos morían. Estas enfermedades eran bastante temidas. Entre las más frecuentes se mencionan: el mal de cámaras (enfermedades diarreicas), el mal de flemas (enfermedades respiratorias), el mal de piedras (dolor en las vías urinarias causadas por cálculos), el mal de orina (enfermedades de vías urinarias), el mal de melancolía (involucraba dolencias mentales y físicas), el mal del sol (insolación), el mal del susto o espanto (síndrome psiquiátrico) y el mal del valle. También habían otras enfermedades que eran más graves, entre ellas se menciona a la terciana (fiebre intermitente que se repite cada tres días), la cuartana (fiebre de origen palúdico, que se acompaña con escalofríos y se repite cada cuatro días), el enfriamiento (resfrío común o gripe), la gota (enfermedad caracterizada por edema y dolores en las articulaciones), la hidropesía (acumulación anormal de líquido seroso en el tejido celular subcutáneo o en cualquier parte del organismo), la apoplejía (suspensión súbita más o menos completa de la función 
cerebral debido generalmente a lesiones de los vasos sanguíneos del encéfalo o de las meninges ), la perlesía (parálisis o debilidad muscular de todo o una parte del cuerpo), el tabardillo (tifus), el pasmo ( enfermedad que se caracteriza por resfriado, dolor de huesos y otras molestias. También se conocía a una enfermedad que cursaba con suspensión o pérdida de los sentidos y de los movimientos) y el cáncer (tumor maligno incurable).

Las pestes (epidemias). Eran enfermedades infectocontagiosas mortales; cuya etiología era desconocida en aquel tiempo. Se presentaban repentinamente, aunque algunas ya se esperaban como sucedía con la viruela, que todos los años reaparecía y se atribuía a la llegada de nuevos negros al Perú. Estas pestes generalmente tenían nombres antojadizos, como es el caso de la alfombrilla, que fue una epidemia parecida al sarampión y que dio muchos enfermos a Martín de Porras, pues postró a setenta novicios en la enfermería del convento de Nuestra Señora del Rosario.

Es pertinente mencionar que la medicina que trajeron los conquistadores españoles al Perú fue, como lo señala Cabieses, inferior a la medicina de los aborígenes peruanos, situación que permaneció hasta las primeras décadas del virreinato. (11) Los recursos terapéuticos de los ibéricos eran mucho más limitados que los conocidos por los aborígenes peruanos, diestros en el empleo de plantas medicinales. El padre Bernabé Cobo, cronista español, reconoce la destreza de los nativos cuando expresa: "En lo que eran expertos fue en curar heridas, para lo cual conocian hierbas extraordinarias de gran virtud." (12) El padre Joseph Acosta, también cronista español, encumbra la pericia de los nativos cuando escribe: "Aún muchos años después de la conquista, los indios tenían mejores conocimientos que los médicos (españoles) de profesión." (13) Por su parte, el cronista peruano Garcilaso de la
Vega (13) hace ver la inclinación o preferencia que tenían los españoles por la medicina peruana, cuando refiere que: "Los españoles hacían curar a sus heridos con frecuencia por los indios." (13) Esto induce a pensar, como se verá más adelante, que una parte del éxito que tuvo Martín de Porras curando enfermos, se deba al conocimiento de los efectos curativo de las plantas, que el mismo cultivaba.

\section{Datos Biográficos de Martín De Porras RELACIONADOS CON la Cirugía}

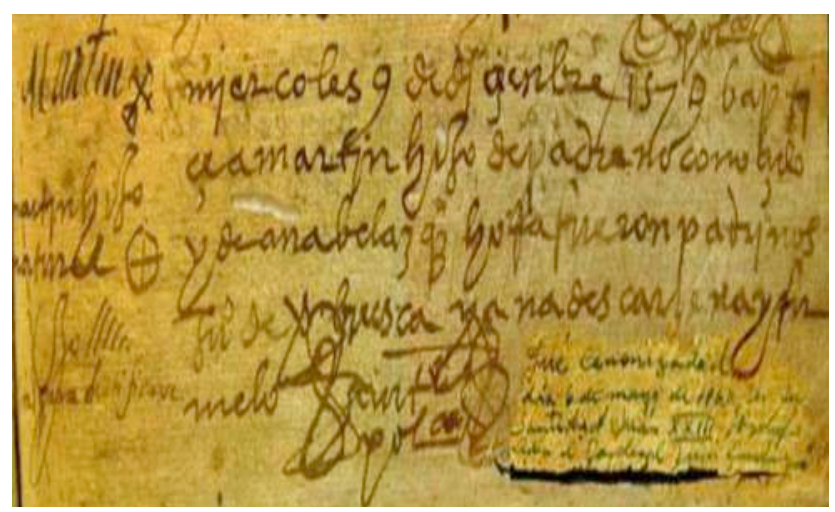

"Miércoles 9 de diciembre de 1579, bauticé a Martín, hijo de padre no conocido y de Ana Velásquez, horra. Fueron padrinos Juan de Briviesca y Ana de Escarcena. Rúbrica, Antonio Polanco. Párroco". En la parte lateral: "Martín hijo natural".

Partida de Bautismo de San Martín de Porras realizada en la Iglesia San Sebastián de Lima, custodiada en el Archivo Arzobispal de Lima.

Los biógrafos de San Martín de Porras, en el mundo terrenal Martín de Porras Velásquez, como el médico mulato limeño Juan Manuel Valdés, el jesuita Rubén Vargas Ugarte, el historiador JoséAntonio delBusto Duthurburu, entre otros, nos brindan datos sobre la relación de este santo peruano con la medicina. ${ }^{(1,2,4)}$

Datos que se encuentran en el Expediente del Proceso de Beatificación de Fray Martín de Porras. ${ }^{(15)}$ 
Relatan que siendo Martín de Porras aún adolescente y deseoso de aprender un oficio y ganar dinero para ayudar a su madre entró a servir en casa del boticario don Mateo Pastor. Martín fue un hábil aprendiz que progresó rápidamente. Con Mateo Pastor aprendió la preparación de medicamentos y asimiló sus efectos medicinales. Y, como en aquellos tiempos las boticas eran centros que hoy se llamarían de primeros auxilios, también aprendió a mitigar los dolores de los enfermos que allí acudían. Se hizo también herbolario y esta fue quizá la fuente primaria o esencial de sus recursos terapéuticos que después le sirvieron para curar muchos enfermos.

Después, considerando que su trabajo sería más útil para la sociedad, decidió aprender el oficio de barbero que conllevaba conocimientos de cirugía menor. Martín aprendió a realizar sangrías, extraer dientes, suturar heridas, aplicar enemas, ventosas, cataplasmas, ungüentos $\mathrm{y}$ otras habilidades para curar enfermos.

Se dice que Martín de Porras practicó el oficio de barbero con Marcelo de Ribera, cirujano de profesión. Este cirujano declaró en el Proceso de Beatificación de Fray Martín de Porras, conocer a Martín desde los diez años de edad; por lo tanto, es lógico pensar que efectivamente con él aprendió el oficio de barbero. ${ }^{(15)}$

Gregorio Marañón cree que Martín fue un alumno provechoso de un maestro barbero de la capital pero que no se conoce si tuvo título otorgado por jurado examinador alguno. (16) Manifiesta también, que fue un barbero por práctica y reconocido por todos, pero graduado por nadie; y, que ejerció ese arte, quizás, amparándose en la Pragmática (Ley) de 1588, que otorgaba el título por cuatro escudos de oro.
A pesar que Martín había aprendido mucho en el arte de la barbería, no fue feliz como aprendiz de barbero. No le disgustaba la barbería, como no le había disgustado la botica, pero tampoco le atraía al extremo de quererle dedicar la vida entera. (4) Por lo que, atraído por la vida religiosa decide, a los 15 años de edad, ingresar a formar parte de la Orden Religiosa fundada por Santo Domingo de Guzmán, hecho que así sucedió, siendo consciente que ayudando a la gente, especialmente a los más pobres, servía a Dios.

Martín de Porras ejerció el oficio de curar enfermos por más de 30 años. Su actividad la desempeñó siempre en la Enfermería del Convento Nuestra Señora del Rosario de Lima, de la Orden Religiosa Santo Domingo de Guzmán. Aquí atendía a los religiosos que vivían en el convento, que eran alrededor de 200 personas. Atendía también a laicos de Lima, entre los que estaban los pobres, negros e indios, así como alguna gente adinerada que estaba segura de encontrar en él la curación definitiva; y, siempre lo hizo gratuitamente.

Valdizán cuenta que una epidemia que atacó a Lima, entró también al Convento de la Orden de Santo Domingo y enfermaron sesenta personas entre religiosos y sirvientes: " $\mathrm{La}$ enfermería parecía una casa de locos, los enfermos gritaban, salian de la cama, saltaban y otras cosas, como si habian perdido el juicio." (3) Martín de Porras los tranquilizaba, les daba su medicina, sus alimentos, aunque los enfermos se resistían por su estado mental. Fueron días duros, pero con la ayuda del Señor Martín atendía puntualmente a los enfermos.

La labor de curar enfermos debió iniciarla entre 1604 y 1610. Los conocimientos que adquirió Martín de Porras de adolescente con el boticario Mateo Pastor, y la habilidad para conocer las propiedades curativas de las 
plantas, le permitió que las curaciones que realizaba sean eficaces. $(4,17)$

Él mismo cultivaba las plantas medicinales que utilizaba en las curaciones. En la huerta del convento cultivaba la hierba de Santa María, que servía para curar heridas inflamadas; en las Lomas de Amancaes cultivaba la manzanilla que servía para curar dolencias digestivas. En la hacienda Limatambo también cultivaba hierbas que eran necesarias para la botica de la enfermería del convento. Pero, no solamente cultivaba las plantas medicinales y curaba a la gran cantidad de enfermos que acudían a él, sino, sobre todo, porque las regalaba a los pobres.

Para ejercer la labor de curar enfermos Martín utilizaba los medicamentos convencionales; no obstante, algunas veces empleaba los más insólitos remedios y recursos, desde ladrillos calientes, tierra raspada de pared, saliva, hasta clara de huevos, chuño, vinagre, panal de rosas y azúcar, pasando por sorbos de agua caliente e inmersiones de agua tibia y caliente. Lavaba heridas con vino y romero triturado, aplicaba hojas de plátano, administraba polvo de sapos calcinados y daba de beber agua mezclada con sangre de gallo negro.

Martín de Porras ejercía de cirujano porque conocía el arte de cirugía, la que aprendió al lado del cirujano Marcelo de Ribera cuando era aprendiz de barbero. Trataba eficazmente los casos de cirugía menor. La cirugía mayor solo la realizaba en casos de emergencia que, afortunadamente, no eran muy frecuentes. Por eso lo reconocieron como enfermero, barbero y cirujano de la enfermería, aunque la opinión general lo ascendió a enfermero y cirujano del convento.

Las funciones de barbero cirujano las cumplía oportunamente gracias a los instrumentos que siempre portaba consigo dentro de una bolsa de cuero de color obscura que la portaba en el cinturón. Entre los instrumentos más importantes estaban la lanceta para las sangrías, la puntilla para cortar y el gatillo para extraer dientes.

Las actividades que desempeñaba Martín como barbero cirujano fueron las siguientes: estéticas (en varones), curativas y preventivas. Las actividades estéticas eran las más solicitadas; incluían cortar el cabello, rasurar la barba, embellecer el bigote y rapar la cabeza de los religiosos del convento. Las actividades curativas, eran las más delicadas; incluían realizar sangrías, extraer dientes, drenar abscesos, realizar vendajes, inmovilizar huesos fracturados, extirpar lobanillos (tumores benignos), succionar heridas sangrantes, suturar heridas, administrar enemas, aplicar ventosas, aplicar ungüentos, fijar cataplasmas, curar cualquier tipo de heridas (quemaduras, heridas infectadas, etc.), bajar la fiebre y tomar el pulso a los enfermos. Las actividades de prevención incluían el recortar el cabello a los niños para prevenir o combatir los piojos, y la de alimentar y asear a las personas para evitar las enfermedades.

Con el transcurrir de los años Martin de Porras progresó mucho en el arte de la cirugía, gracias a sus conocimientos, destreza y diligencia en ese arte, por eso, también se le reconoció en la Lima virreinal como cirujano romancista o cirujano menor.

\section{Métodos Terapéuticosos de Martín De Porrras}

Si examina el expediente del Proceso de Beatificación de Fray Martín de Porras, en el que se presenta testimonios de personas que habían sido curadas por Martín o que habían sido testigos de curaciones que él hizo, 
se puede manifestar que este santo mulato empleó los siguientes métodos terapéuticos: oración, medicamentos convencionales, imposición de manos, quirúrgicos, insólitos y mixtos, todos ellos eficaces. ${ }^{(15)}$ Es conveniente precisar que los ejemplos de curaciones que se presentan son algunos de los que se describen en el mencionado mediante la oración.

\section{LA ORACIÓN, SUPREMO MEDICAMENTO.}

A los enfermos los encomendaba a Dios y a su Madre Santísima, y las curaciones no tardaban en realizarse. Martín era en esto tan solícito, y era tanta la humildad con que lo pedía, que el Señor siempre lo complacía. José Valdés, médico peruano mulato y uno de sus más conspicuos biógrafos, destaca que cuando Martín de Porras curaba a sus enfermos, siempre lo hacía hincado de rodillas, con tanta humillación y respeto, como si cada paciente fuese el mismo Jesucristo. ${ }^{(1)}$ Además, producto de su fe, bendecía con la señal de la cruz a los enfermos, e imploraba a Dios Todopoderoso para que sanaran.

Un ejemplo de método terapéutico mediante la oración, se puede mencionar la de un hombre pobre, enfermo de gangrena en ambas piernas, que no mejoraba con los medicamentos que recibía. Su figura era repugnante, el olor que despedían las piernas enfermas no la podían tolerar las narices mejores dispuestas y acostumbradas a esos aromas, y el dolor de las heridas era intenso que el infeliz enfermo gritaba. Martín recurrió a la señal de la Cruz. Levantó su mano, puso los ojos en el cielo y trazó sobre las piernas del enfermo el sagrado signo de la Cruz. Aquella piel rojiza, aquellas llagas purulentas, aquel hedor intolerable, aquellos dolores insufribles desaparecieron como por magia. El enfermo se levantó rápidamente y su alegría no tuvo límites. El nombre de Martín de Porras corría de boca en boca, y el curado relataba el hecho a cuantos encontraba.

Aplicación de medicamentos convencionales, especialmente de origen vegetal.

Ya nos hemos referido sobre el aprendizaje que Martín tuvo con el boticario don Mateo Pastor. El estudio de las plantas fue tan intenso que le permitió conocer rápidamente sus efectos medicinales, que con seguridad los dosificaba perfectamente para beneficio de la gran cantidad de enfermos que recurrían a él.

Un ejemplo de curación con aplicación de medicamentos, es la realizada al joven novicio fray Luis Gutiérrez. Cierto día fray Luis Gutiérrez, accidentalmente, con un cuchillo sufrió heridas en dos dedos de la mano izquierda. La sangre fluía abundantemente sin poderla contener. El joven gritaba y se retorcía de dolor. En aquel momento, guiado por Dios y sin que nadie lo hubiese llamado, entró Martín al convento. Examinó las heridas del novicio, y le dijo: "No temas hijo mí; el Señor que tiene el poder sobre la vida y sobre la muerte, sabrá curar tus heridas, no importa lo graves y peligrosas que ellas sean." Como la sangre continuaba brotando de las heridas, Martín acudió a sus frascos, tomó unos polvos (yerbas de Santa María), los echo sobre los dedos y aquella quedó detenida. Hizo sobre la mano del enfermo la señal de la Cruz, invocó a la Santísima Trinidad, y fray Luis Gutiérrez quedó con los dedos perfectos, enteros y sanos.

Otro ejemplo, es el caso de su jefe inmediato superior de enfermería, fray Fernando Aragonés, quien había recibido los santos óleos pues estaba desahuciado por presentar un mortal dolor en el costado, probablemente causado por neumonía. Martín de Porras acudió a verlo, le dio agua para que bebiera y le puso las manos en el costado, fajándole con una venda y en ella unos cogollos de alfalfa, y 
de inmediato despareció el dolor, quedándose dormido. Este hecho lo contó el mismo fray Fernando Aragonés sano y salvo cuarenta años después. Él contó también que le vio sanar muchos dolores con solo poner sus manos.

\section{IMPOSICIÓN DE MANOS.}

El método terapéutico que más admiración y popularidad produjo fue la imposición de manos, método que empleaba Jesús de Nazaret. ${ }^{(18)}$ Los enfermos estaban seguros que Martín de Porras los curaba definitivamente imponiéndoles las manos.

Cuando Martín de Porras aplicaba sus manos sobre la parte enferma o doliente del enfermo, la curación era eficaz e instantánea. ${ }^{(19,20)}$ Por ejemplo, el caso en que evitó que a fray Pedro de Montes de Oca le amputaran una pierna gangrenada. Fray Pedro Montes de Oca tenía una pierna gangrenada, por lo que el médico que lo trataba recomendó la amputación inmediata. El religioso no se resignaba a la amputación pero comprendía la necesidad de operarse. Se quejaba de dolor y se mostraba impaciente que los religiosos del convento ni siquiera atrevían hablarle mucho. Martín entró a al dormitorio con la serenidad, y rápidamente se dio cuenta que no era dolor lo que tenía Montes de Oca sino una fiebre altísima que padecía. El enfermo deliraba, y en medio de su delirio manifestó el deseo de comer una ensalada. Martín se la preparó, fresca y deliciosa. Cuando comió la ensalada le bajo la fiebre y recobró el buen humor. Luego pidió a Martín que le aplicara su mano a la pierna gangrenosa. Martín vio la pierna y le puso las manos en ella, con lo cual quedó sano y libre de lo que le afligía.

Otro ejemplo es la curación de fray Luis de Guadalupe que padecía de una grave neumonía que le causaba dificultad respiratoria. Ante la ineficacia de los medicamentos que recibía y la gravedad de la enfermedad, fray de Barbarán lo confesó y le dio los santos óleos. En ese momento fray Martín de Porras sonriendo entró al dormitorio llevando algunas medicinas para aplicárselas al enfermo. Fray Luis Guadalupe que había visto cómo las anteriores medicinas no le habían hecho efecto le dijo a Martín de Porras: "Deja a un lado tus medicinas y aplica tu mano en mi costado, pues siento intenso dolor." Martín cedió ante la súplica del enfermo. Y, fray Pedro de Guadalupe quedó sanó de inmediato.

Fray Cipriano de Medina fue testigo de la curación de monseñor Feliciano de Vega, obispo de La Paz y electo arzobispo de México. El obispo Feliciano Vega estaba desahuciado por todos los médicos, quienes recomendaron que le dieran la comunión y los santos óleos. El obispo que no conocía a fray Martín pero había oído hablar de él y de sus afamadas curaciones, pidió al prelado de los dominicos que se lo enviaran para que lo tratase de un fuerte dolor de costado y de fiebre. Fray Martín fue con fray Cipriano de Medina, quien refiere así lo que entonces sucedió: Habiendo ido y entrado a la pieza donde estaba disgustado el obispo. En presencia de su familia y de otros el obispo comenzó a reprender a fray Martín porque no lo había visitado. Martín se arrojó a tierra sin pronunciar palabra. El obispo le hizo una señal para que se levantase y le pidió que se acercase a la cama y que le diese la mano. Martín respondió: “PPara qué quiere un príncipe la mano de un pobre mulato donado?" El obispo le dijo: “ ¿No os ha mandado el prelado hagáis lo que yo dijere?" Y respondió: "Sí señor. Pues poned la mano en este lado donde tengo el dolor." $\mathrm{Y}$, luego al punto se sintió sin dolor, poniéndole la mano fray Martín. Reconociendo él la acción, se turbó y se le puso el rostro muy colorado y comenzó a sudar en extremo y dijo: " ¿No basta ya, señor?" El arzobispo respondió: "Dejadla estar donde la he puesto." Y estando otro rato así, 
se halló del todo aliviado, libre de la calentura con admiración grande de los presentes y mucho mayor de los médicos que volvieron por la tarde y, a voces, unos y otros decían que era una maravilla que Dios había obrado por este siervo suyo.

Imponiendo sus manos, también curó a fray Fernando Aguilera. El religioso se encontraba muy debilitado con dolor de estómago, mandó llamar a Martín de Porras, acudiendo este a socorrerlo, y con solo ponerle las manos sobre el estómago quedó bueno y sano. Lo mismo sucedió cuando curó a fray Antonio Otero de un persistente hipo y que la curación se le atribuyeron a unas ventosas que le aplicó Martín de Porras. El mismo fray Antonio Otero tuvo que aclarar, diciendo: "Esta mejoría y salud atribuyo al contacto de las manos del dicho siervo de Dios (Martín de Porras)."

Métodos quirúrgicos: Sangrías, curaciones de heridas, extracción dentaria, inmovilización y reducción de fracturas óseas, entre otros.

Un ejemplo de método quirúrgico es el que fue realizado a su maestro, el cirujano Marcelo de Rivera. En el Proceso de Beatificación de fray Martín de Porras, Marcelo de Rivera declaró que, siendo él mancebo, le ocasionaron una estocada en el párpado inferior derecho, quedando el ojo fuera de su lugar colgando y que Martín de Porras curó la herida. ${ }^{(15)}$ También, manifestó que a los tres días quedó bueno y sano.

El mismo cirujano Marcelo de Ribera testifica lo siguiente: "Cierto día a un indio le dieron una puñalada que le vaciaron las tripas; y que Martín de Porras envió por mi para que curarse al herido. Como no me encontraron, Martín lo curó y puso al paciente en la enfermería de los negros del convento. Los religiosos del convento avisaron al padre Prior que Martín traía enfermos de afuera a curar, indios y negros pobres. El Prior ordenó que echasen fuera al herido, Martín llevó al herido a casa de una hermana que vivía a una cuadra del convento. Le dio pasas, pan y conservas, y le dijo que enviaría al cirujano a curar al a este testigo. Al día siguiente fui a curar a curar al indio, y no le encontré herida más que una raya colorada, y bueno y sano al indio."

Otro caso es la de una pelea de dos negros de Lima, en la que uno de ellos resultó con un traumatismo abdominal abierto con exposición de vísceras huecas. Francisca, una negra esclava fue testigo ocular de la curación. Ella declara: "Traía el miserable colgando lastimosamente las tripas. Algunas personas misericordiosas lo llevaron a la enfermería del convento para que Martín de Porras lo curase, cosa que asi sucedió. Martín de Porras se puso de rodillas delante del herido y con su boca le succionó la herida sacándole sangre. Enseguida le lavó la herida con vino, le puso romero molido, y luego fue enviado a su casa." Alos cuatro días, la negra Francisca lo vio bueno y sano, quedando maravillada al ver que siendo la lesión tan grave había curado rápidamente solo con vino y romero.

Otro método netamente quirúrgico es la extracción de cuerpos extraños. El sargento Francisco de la Torre, en el Proceso de Beatificación de Martín de Porras declaró haber visto al beato Martin extraer un hueso de la garganta de uno que estaba como muerto.

Una de las muchas curaciones de tipo odontológica que Martín de Porras realizó es la de fray Alonso de Arenas cuando era novicio. El novicio presentaba un dolor de muela tan intenso que no le dejaba comer ni dormir, por lo que tuvo la necesidad de llamar a Martín de Porras, que era cirujano, para que se la sacase. Estando el doliente sentado sobre el piso y Martín parado con el gatillo en la mano lista para sacarle la muela, le mete el dedo a la boca y le pregunta cuál era la muela. El novicio le indicó. Martín de Porras puso su dedo sobre la 
muela causante del dolor, y al retirar el dedo el novicio le dijo que el dolor de muela había desaparecido. Martín se retiró sin sacársela, y por mucho tiempo Fray Alonso de Arenas no presentó dolor.

\section{MÉTODOS INSÓLITOS, APARENTEMENTE INEFICACES}

Algunas veces Martín de Porras usaba en sus curaciones medios a todas luces ineficaces para curar pero que, para satisfacer la fe de los enfermos, sin engaños se los proporcionaba solamente como alivio y, sin embargo, surtía efectos curativos.

Por ejemplo, su sobrina Catalina relata que trajeron de la chacra a casa de su madre en Lima a un negro porque le habían producido una herida en la cabeza. Habiéndole dado no menos de ocho puntos en ella, quedando solapada la herida, puso al enfermo en los últimos alientos de la vida. Mandaron llamar a fray Martín para que lo atendiera. Estando Martín en casa de su sobrina, sacó la llave que traía de su celda y, raspando la pared, cogió un poco de tierra y se la colocó en la herida haciendo la señal de la cruz sobre ella; luego tomó un pedacito de lienzo, lo humedeció con su saliva y le puso en la herida como parche. Al retirarse Martín le dijo que estará bien, hecho que así sucedió, pues a los pocos días, sin otro medicamento ni hacer otra curación, el negro estuvo bueno y sano.

Otro ejemplo es el que narra el mismo beneficiado, el capitán Juan de Guarnido. Este declara que hallándose con el pie y la pierna derecha hinchados, con granos en forma de diviesos que drenaban secreción purulenta y con intenso dolor, envió a llamar al venerable hermano fray Martín para que le viese y le aplicase alguna medicina. Martín después de haberlo visto, le dijo que no era nada y haciéndole la señal de la cruz con saliva en la pierna y pie enfermos, sin otra medicina, las lesiones desaparecieron inmediatamente. El capitán quedó completamente sano y dio infinitas gracias al Señor por las mercedes que ha recibido por intercesión de su siervo Martín. La siguiente curación tiene como testigo a Juan de la Parra, quien refiere que cierto día al llegar él con fray Martín a la chacra del español Francisco de Cáceres Manjarrés, les salió al encuentro un hombre negro alto. Fray Martín le pregunta: "Hijo, chay algún enfermo aqui?". El negro le respondió: "Sí, padre, mi mujer está muy achacosa de un flujo de sangre en las partes bajas y la olearon (dieron la extremaunción) hoy al mediodía." Los llevó a su rancho donde estaba postrada su mujer y allí la vio fray Martín. Ella dijo que había rodado, desde las lomas, con un caballo cargado de leña, y que el animal le había caído encima de ella. Fray Martín respondió: "Hija, no te desconsueles que todo se te quitará con la ayuda de Dios." Llamó al negro y le dijo que de una acequia atrapase tres sapos vivos, y que los quemara dentro de una olla sin que saliese humo. Cumplido lo ordenado. Martín muele los sapos quemados, y ya hechos polvos los envuelve en un trapo y se los cuelga en la cintura a la enferma, diciendo: "Hija, yo te curo y Dios te sane." Al día siguiente Juan de la Parra vio a la mujer, esta le dijo: "He dormido muy bien toda la noche, a Dios gracias, con la cura que me hizo el padre de santo Domingo, Dios se lo pague."

Como método insólito también se debe mencionar una curación con ladrillos calientes. El tallador Francisco Pérez Quintero declaró que se hallaba atacado de una terciana doble muy rebelde y que era asistido de ellas por el doctor Navarro, médico de esta ciudad (Lima), el cual lo había desahuciado. Dice el testimonio que el beato Martín le aplicó dos ladrillos muy calientes en el vientre y le curó por completo de la penosa dolencia. 
Así mismo, se puede señalar la curación con sangre caliente de gallo. El informante fue Fernando de Valdez, quien declaró haber visto curar una erisipela, aplicando el beato Martin la sangre caliente de un gallo, recientemente victimado, sobre la región enferma.

\section{Métodos curativos MiXtos}

Había circunstancias, las que no eran pocas, en que Martín de Porras combinaba cualquiera de los métodos anteriores para curar a los enfermos que acudían en su ayuda.

Un ejemplo de este método curativo nos los cuenta Francisco Pérez Quintero que fue testigo presencial de la curación. Él manifiesta que el señor Juan de Villafuerte tenía una hija de cuatro años de edad que estaba enferma y desahuciada; y, que a la niña la llevaron a la portería del convento para que fray Martín la viera. El religioso indicó que le quitasen los medicamentos que tenía puesto por prescripción de su médico tratante. Martín habiendo vertido un poco de saliva en su mano, le frotó el estómago y le hizo muchas cruces, diciéndole que no sería nada y que no moriría de aquella enfermedad. Luego ordenó o prescribió como tratamiento que bañasen a la niña con un poco de agua tibia y, que después le pusiesen en el estómago una hoja de plátano. Indicación que los padres efectuaron. A las 24 horas, la niña presentó un vómito de gran cantidad y luego quedó completamente sana.

Otro caso es el referido por el capitán Juan de Guarnido. Este capitán declara que había en el convento un religioso "donado" de oficio zapatero que tenía un brazo enfermo que cada mes se le llenaba de apostemas (abscesos); y que él lo llevó a fray Martín para que lo curase. Fray Martín, comenzó con saliva a hacerle unas cruces en la apostema. El "donado" al ver que no le ponía algún parche o medicamento o que no le hacía otra cosa más que las dichas cruces, se enojó. Martín, para consolarlo cogió un pedazo de bota en que se echa vino y cortó como parche y se lo puso en la apostema, haciendo otra vez con saliva las dichas cruces. El capitán le dijo al enfermo que no se afligiese y que no se quitase el parche y así lo hizo. Al día siguiente, el religioso "donado" estaba bueno y sano; y de contento decía a voces que el dicho venerable hermano era un santo varón y que había obrado Dios con él, por su intercesión, un milagro patente. El "donado" en reconocimiento le confeccionó al hermano Martín un par de zapatos nuevos, que de ninguna manera los quiso recibir y le pidió que se los diese a un pobre.

Relatar todas las curaciones realizadas en vida por San Martín de Porras mediante los diferentes métodos terapéuticos, sería de nunca terminar. Por eso, nos detenemos aquí, con la seguridad de haber alcanzado el objetivo trazado.

\section{El Cirujano Martín De Porras}

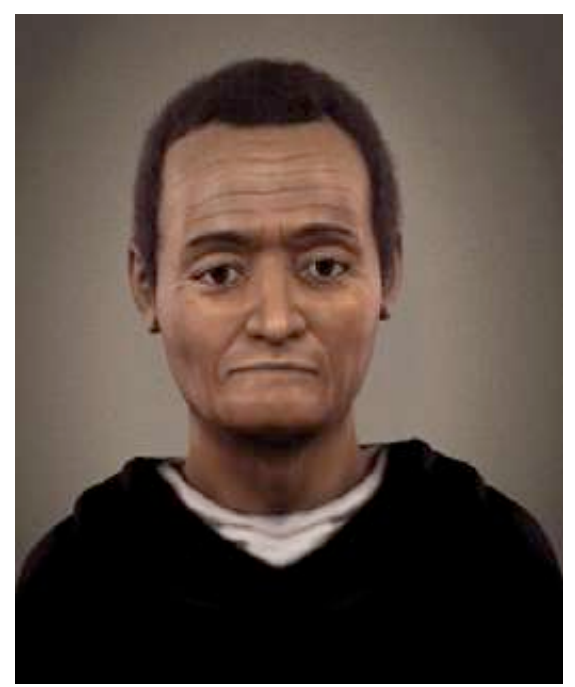

Posible rostro de San Martín de Porras según la tecnología. Reconstruido en 3D a partir del cráneo de santo limeño, por el equipo brasileño de Antropología Forense y Odontología Legal y por científicos de las universidades San Martín de Porras e Inca Garcilaso de la Vega. 
Por todo loexpresado se puede decir queexisten razones o hechos históricos que inducen a inferir que San Martín de Porras, santo mulato peruano, ejerció la cirugía en Lima entre los siglos XVI y XVII. A continuación, señalaremos algunos de los hechos más importantes.

a) Criterio de inclusión: En la Lima virreinal, lugar y época de la vida terrenal de san Martín de Porras, la institución suprema que controlaba el ejercicio de los profesionales de la salud era el Real Tribunal del Protomedicato. Esta institución incluía a los barberos, como Martín de Porras, en la categoría de cirujanos romancistas. Estos trataban enfermedades externas (quirúrgicas) de menor complejidad. Se le exigía cuatro años de práctica al lado de un cirujano titulado. No se les exigía estudios de latín ni de humanidades como a los cirujanos latinos. Rendían sus exámenes en buen romance, es decir en idioma castellano. El maestro de Martín de Porras fue, como ya hemos manifestado líneas arriba, el cirujano Marcelo de Ribera. No ha sido posible determinar el tiempo de permanencia con su maestro; ni mucho menos se ha determinado si Martín obtuvo el grado de Cirujano Romancista, todo indicaría que no. Lo que sí está acreditado por muchos testigos de su época que Martín ejercía de cirujano, con o sin título, porque conocía el arte de la cirugía. ${ }^{(15)}$

b) Adiestramiento: Martín de Porras en su adolescencia adquirió conocimientos médicos quirúrgicos. Con Mateo Pastor, boticario de Lima, adquirió conocimientos de farmacología. Con él aprendió a preparar medicamentos y asimiló también sus efectos medicinales. Se convirtió en herbolario, recurso terapéutico que le sirvió después para curar diligentemente a muchos enfermos. Con Marcelo de Rivera, cirujano de profesión, aprendió el oficio de barbero, que conllevaba conocimientos de cirugía menor, además de cortar el cabello y rasurar la barba. Actividades quirúrgicas que ejerció por más de 30 años.

Es importante mencionar también, como sostiene Valdizán ${ }^{(3)}$, que la universidad de Fray Martín de Porras fue entre el mercado con sus vendedores de plantas medicinales, el convento con el elevado espíritu de caridad y sus profundos sentimientos religiosos y el pueblo, cuya observación y por cuyo afecto, Martín llegó a desarrollar sus innatas cualidades intuitivas de clínico, por el acierto que tuvo en conocer enfermedades $\mathrm{y}$, desde luego, aplicar los remedios conocidos.

c) Testimonios de su labor quirúrgica: En el expediente del Proceso de Beatificación de Fray Martín de Porras existen numerosas e importantes declaraciones de personas que fueron curadas o que han sido testigos de curaciones realizadas por Martín. ${ }^{(15)}$ Declaraciones que no dejan dudas sobre la práctica quirúrgica que desempeñó el santo mulato peruano.

Su maestro, el cirujano Marcelo de Ribera, declaró conocer a Martín desde los diez años de edad; por lo tanto, es lógico pensar que efectivamente con él aprendió el oficio de barbero. Declaró también que cuando él era mancebo, presentó una herida en el párpado inferior derecho quedando el ojo colgando, herida que Martín curó. El testimonio del cirujano Marcelo de Ribera, induce a pensar dos hechos: Primero, que Martín tendría entre 12 y 13 años de edad cuando comenzó aprender el arte de la barbería; y segundo, que su maestro Marcelo de Rivera cuando presentó la herida, confió en su alumno Martín, probablemente porque lo consideraba experto en la cirugía. 
El licenciado Bernardo de Esplana, declaró, que "Fray Martín de Porras, antes de ingresar en la religión de Santo Domingo, ejercía solamente la profesión de barbero y que, al haberle encomendado la enfermería del convento del Rosario, ejerció de enfermero, barbero y cirujano." Valdizán, refiriéndose a este testimonio manifiesta que el licenciado Esplana comunica la diversidad de oficios atribuidas a Fray Martín. ${ }^{(3)}$ Manifiesta también que Martín antes de hacerse dominico era barbero y ya en la religión, por razones de piedad y por tener a su cargo la enfermería del convento, tuvo que desempeñar las funciones de enfermero barbero, y cirujano.

Otra declaración fue la de Juan Vásquez, quien manifestó que "viéndose enfermo y que no tenía asilo alguno sino el de Dios, estuvo obligado a asistir a la habitación de fray Martín de Porras; y por ser Maestro Barbero, le enseñó a este testimonio dicho arte, y para esto le dio algunas lecciones de aquellas que son necesarias y comenzó a ejercitar dicho arte." Agregó que viajó a Chile; y que, después de algún tiempo, al regresar al Perú su primera visita había sido para su protector y su maestro fray Martín de Porras.

El mismo Valdizán nos informa de un hecho que puede considerarse como demostración indirecta de la labor quirúrgica de Martín de Porras. "Él refiere que el licenciado Pedro de Urdanivia, cirujano aprobado por el Tribunal del Protomedicato del Virreinato, que gozaba de gran crédito en Lima en la segunda mitad del siglo XVII, había recibido de la viuda del cirujano Marcelo Ribera (maestro de Martín de Porras), una lanceta que Martín de Porras le habia obsequiado. Urdanivia la guardaba con verdadera veneración y la llamaba la postemera, probablemente por el uso al cual había sido destinada." (3)

\section{Conclusión}

Martín de Porras Velásquez era más santo que hombre, un santo que curaba a los enfermos mediante métodos quirúrgicos que él aprendió en su adolescencia con la inspiración o iluminación del Supremo Sanador. Sus conocimientos médicos fueron fruto de estudio, dedicación e inteligencia y no de facultades misteriosas. Era un médico de cuerpos y de almas como lo fue Jesús de Nazaret en Palestina. Curaba a los enfermos, algunas veces con medicamentos convencionales provenientes de la naturaleza, especialmente del reino vegetal; otras veces con imposición de sus manos, incluso con medios aparentemente ineficaces, pero siempre orando y haciendo cruces en nombre de Dios.

Teniendo en consideración los criterios de inclusión de la cirugía de aquellos tiempos estipulada por el Real Protometicato del Perú, y según el conocimiento y práctica que exigía esta especialidad, se puede afirmar categóricamente que Martín de Porras por ser barbero realizó la función de cirujano romancista, y lo hizo de una manera eficaz y efectiva.

A los profesionales de la medicina nos deja el mensaje que nuestra profesión la debemos ejercer con presencia vigilante y solícita al lado de los enfermos, pues la actividad médica se funda sobre una relación interpersonal, en la que un hombre afligido y enfermo confía en otro hombre que puede hacerse cargo de su necesidad y que lo va a encontrar para asistirlo, cuidarlo y sanarlo, como hizo Martín de Porras con miles de enfermos.

\section{REFERENCIAS BibliográficAS}

1. Valdez, José Manuel: Vida Admirable del Bienaventurado Fray Martín de Porras. Lima: Grafica Smart, séptima edición, 1951.

2. Vargas Ugarte, Rubén: El Beato Martín de Porras. Lima: Imprenta Santa María, 1961.

3. Valdizán, Hermilio: Martín de Porras, el Cirujano. Lima, 1916. Busto Duthurburu, José Antonio del: San Martín de Porras. Lima: Fondo Editorial de la Pontificia Universidad Católica del Perú, 2001. 
4. Peña Benito, Ángel: San Martín de Porras el Médico de Dios. https: / / fraymartindePorras.wordpress.com/2011/09/12/ san-martín-de-Porras-el-médico-de-dios.

5. Delgado Matallana, Gustavo y Rabí Chara, Miguel: Evolución histórica de la Facultad de Medicina de San Fernando de la Universidad Mayor San Marcos. Lima: Centro de Producción Editorial e Imprenta de la UNMSM, 2006: 17-84.

6. Pamo Reyna, Oscar: Medicina en la época virreinal. www. limateca.org/ ...2007 Medicina en la época colonial 1535-1821 Oscar Pamo Reyna.pdf.

7. Lastres, Juan B.: Historia de la Medicina Peruana: La Medicina en el Virreinato Vol. II, Lima: Imprenta Santa María, 1951.

8. Valdizán, Hermilio: Apuntes para la bibliografía médica peruana. Lima, 1928.

9. Suardo, Juan Antonio. El Diario de Lima. Lima: Imprenta Lúmen, 1963.

10. Cabieses Molina, Fernando: La Salud y los Dioses: La medicina en el Antiguo Perú. Lima: Fondo Editorial de la Universidad Científica del Sur, 2007.

11. Cobo, Padre Bernabé. Historia del Nuevo Mundo. Madrid: Atlas, 1959/ 1653.

12. Acosta, Joseph: Historia Natural y Moral de las Indias. Madrid: Consejo Superior de Investigaciones Científicas, 2008/1653.

13. Garcilaso de la Vega (Inca). Comentarios Reales de los Incas. Lima: Editorial Fondo de Cultura Económica, 1991/1603.
14. Expediente. Proceso de Beatificación de Fray Martín de Porras. Ed. "Secretariado Martín de Porras", Palencia. Transcripción del original que se conserva en el archivo arzobispal de Lima por el padre Juan de la Cruz Prieto. Los testimonios corresponden a los años 1660, 1664 y 1671.

15. Marañón, Jorge. Vida e historia de fray Martin de Porras. Madrid: Editorial Espasa Calpe, 1958.

16. Bedoya Villacorta, Antolín. Fray Martín de Porras y su Apostolado Hipocrático. Lima, 1949.

17. Paico Vílchez, Emiliano. Jesús Médico de Cuerpos y de Almas. En Paico Vílchez, Emiliano: La Medicina y la Religión: Más cerca que nunca. Trujillo (Perú): Fondo Editorial de la UPAO, 2015.

18. García, Antonio. Biografía breve del beato Martín de Porras (Dominico). Madrid: Ediciones Veritas, 1952.

19. Romero, Emilio. EL Santo de la Escoba: Fray Martín de Porras. Lima: Ediciones Nazaret, 1962. 